\title{
Üriner İnkontinans Bulunan Obez ve Obez Olmayan Kadınların Hayat Kalitelerinin ve Seksüel Fonksiyonlarının Karşılaştırılması
}

\author{
Yeşim AKDEMİR ${ }^{1} \bowtie$, Konul NOVRUZOVA $^{1} \oplus$, Çağatay BÜYÜKUYSAL ${ }^{2} \oplus$, Ülkü ÖZMEN$^{1} \oplus$, \\ Müge HARMA $^{1} \oplus$, Mehmet İbrahim HARMA ${ }^{1}$ (]) \\ ${ }^{1}$ Zonguldak Bülent Ecevit Üniversitesi Tıp Fakültesi, Kadın Hastalıkları ve Doğum Anabilim Dalı, Zonguldak, Türkiye \\ ${ }^{2}$ Zonguldak Bülent Ecevit Üniversitesi Tip Fakültesi, Biyoistatistik Anabilim Dalı, Zonguldak, Türkiye
}

Bu makaleye yapılacak atıf: Akdemir Y, Novruzova K, Büyükuysal Ç, Özmen Ü, Harma M, Harma Mİ. Üriner İnkontinans Bulunan Obez ve Obez Olmayan Kadınların Hayat Kalitelerinin ve Seksüel Fonksiyonlarının Karşılaştırılması. Türk Diyab Obez 2020;2: 84-89.

\begin{abstract}
ÖZ
Amaç: Seksüel fonksiyonlar genel hayat kalitesini etkileyen önemli faktörlerdendir. Özellikle de üriner inkontinanslı hastalarda seksüel fonksiyon bozuklukları asemptomatik kadınlara göre daha sık olarak görülmektedir. Bu çalışmada obezitenin, üriner inkontinans bulunan kadınların hayat kalitelerine ve seksüel fonksiyonlarına etkisi araştırılmıştır.

Gereç ve Yöntemler: Ocak 2020- Nisan 2020 tarihleri arasında, Zonguldak Bülent Ecevit Üniversitesi Sağlık Uygulama ve Araştırma Merkezi Kadın Hastalıkları ve Doğum Anabilim Dalı, Kadın Hastalıkları Polikliniği’ne idrar kaçırma şikayeti ile başvuran kadınlar değerlendirilmiştir. Sorgu formlarını cevaplamayı kabul eden, 18 yaş ve üzerinde, seksüel olarak aktif olan hastalar çalışmaya dahil edilirken, sorgu formlarını eksik cevaplayan, nörolojik ve psikiyatrik hastalığı bulunan, evre 2 ve üzeri pelvik organ prolapsusu bulunan hastalar dışlanmıştır. 67 hastanın, vücut kütle indeksi (VKİ) $\geq 30$ olan 37’si obez grup, VKİ<30 olan 31’i ise obez olmayan grup olarak ayrılmıştır. Çalışmada hayat kalitesi ve seksüel fonksiyonları değerlendirmek için İnkontinans Etki Anketi ('Incontinence Impact Questionnaire, IIQ-7), Ürogenital Distres Envanteri ('Ürogenital Distress Inventory’, UDI-6), Aşırı Aktif Mesane Anketi (Overactive Bladder Questionnaire, OAB-V8) ve Pelvik Organ Prolapsusu / Üriner İnkontinans Cinsel Anketi (Pelvic Organ Prolapse/Urinary Incontinence Sexual Questionnaire, PISQ-12) sorgu formları kullanılmıştır.

Bulgular: Obez ve obez olmayan grupta en sık görülen üriner inkontinans tipi mikst inkontinans (sırasıyla \%54,1 ve \%38,7) olarak belirlenmiştir. Obez hastalarda, obez olmayan hastalara göre daha yüksek UDI-6 total skoru (sırasıyla 58,30 ve 29,16 p=0,001) ve daha yüksek OAB-V8 total skoru (sırasıyla 21,00 ve 12,00 p=0,002) saptanmıştır. IIQ-7 total skorları açısından gruplar arasında fark gözlenmemiştir ( $\mathrm{p}=0,795)$. Öte yandan yüksek skorların seksüel fonksiyonlarındaki iyilik ile ilişkili olduğu PISQ-12 skorları ise obez olmayan grupta obez gruba göre anlamlı olarak daha yüksek saptanmıştır (sırasılla 28,00 ve 27,00 p=0,026). VKİ ile PISQ-12 skorları arasında zayıf negatif korelasyon ( $\mathrm{r}=-0,296, \mathrm{p}=0,027)$, UDI-6 skorları ile orta derece pozitif korelasyon $(\mathrm{r}=0,431, \mathrm{p}<0,001)$ ve OAB-V8 skorları ile orta derece pozitif korelasyon $(r=0,490, \mathrm{p}<0,001)$ olduğu ortaya çıkmıştır.

Sonuç: Seksüel disfonksiyon, üriner inkontinansı bulunan obez hastalarda obez olmayan hastalardan daha yüksek oranda saptanmıştır. $\mathrm{Bu}$ grup hastalarda seksüel disfonksiyon varlığının araştırılması, sorunların öngörülebilmesine olanak sağlayarak hastaların hayat kalitelerinin artırılmasına olanak sağlayacaktır.
\end{abstract}

Anahtar Sözcükler: Üriner inkontinans, Seksüel disfonksiyon, Obezite, Hayat kalitesi

\section{Comparison of Quality of Life and Sexual Functions of Obese and Non-Obese Women with Urinary Incontinence}

\begin{abstract}
Aim: Sexual function is important for quality of life and sexual dysfunction is more common in women with urinary incontinence than asymptomatic women. We evaluated the effect of obesity on quality of life and sexual functions of women with urinary incontinence.
\end{abstract}

ORCID: Yeşim Akdemir / 0000-0002-8574-5065, Konul Novruzova / 0000-0002-5655-1149, Çağatay Büyükuysal / 0000-0001-9810-5633, Ülkü Özmen / 0000-0001-7979-4015, Müge Harma / 0000-0002-4327-674X, Mehmet İbrahim Harma / 0000-0002-9734-5253 
Material and Methods: A prospective case control study was conducted between January and April 2020 at Zonguldak Bulent Ecevit University, School of Medicine, Obstetrics and Gynecology Department. Women who agreed to answer the questionnaires, older than 18 years of age and sexually active were included to our study. Women who had psychiatric or neurological disease, had pelvic organ prolapsus greater than stage 2 and not completed the the questionnaires were excluded. A total of thirthy seven patients were categorized as obese group and thirthy one patients were categorized as non-obese group due to their body mass index. Incontinence Impact Questionnaire (IIQ-7), Urogenital Distress Inventory (UDI-6), Overactive Bladder Questionnaire (OAB-V8), Pelvic Organ Prolapse/ Urinary Incontinence Sexual Questionnaire (PISQ-12) were used to evaluate quality of life and sexual functions.

Results: Mixed incontinence was the most common type of urinary incontinence in both groups (54.1\% vs $38.7 \%$ ). UDI-6 total scores were higher in obese patients than non-obese patients (58.30 vs $29.16 \mathrm{p}=0.001$ ). Also OAB-V8 total scores were higher in obese patients than non-obese patients ( 21.00 vs $12.00 \mathrm{p}=0.002)$. IIQ-7 total scores were similar in both groups ( $\mathrm{p}=0.795)$. On the other hand PISQ12 total scores that positively correlated to better sexual functions, were higher in non-obese patients than obese patients (28.00 vs $27.00 \mathrm{p}=0.026)$. A weak but significant negative correlation between body mass index (BMI) and PISQ-12 scores ( $\mathrm{r}=-0.296, \mathrm{p}=0.027)$, and moderate positive correlation between BMI and UDI- 6 scores $(\mathrm{r}=0.431, \mathrm{p}<0.001)$, and OAB-V8 scores $(\mathrm{r}=0.490, \mathrm{p}<0.001)$ were obtained.

Conclusion: Sexual dysfunction were more common in obese women with urinary incontinence than non-obese women with urinary incontinence. More comprehensive assesment that focusing more to sexual functions would be more suitable to increase the quality of life of patients with urinary incontinence.

Key Words: Urinary incontinence, Sexual dysfunction, Obesity, Quality of life

\section{GíRİ̧}

Gelişen ülkelerdeki ortalama yaşam sürelerindeki artış ile beraber, orta/ileri yaş grubu kadınlardaki obezite oranları artmaktadır (1). Türkiye'de yapılan çalışmalarda kadın popülasyonunda obezite prevalansının \%20-50 arasinda olduğu saptanmıştır (2). Obez kadınlarda kardiyovasküler komplikasyonlar, myokard infarktüsü, inme, tip2 diabetes mellitus, kanser ve osteoporozun daha sık görüldüğü bilinmektedir (3).

Uluslararası Kontinans Derneği (ICS), Üriner İnkontinans'1 sosyal ve hijyenik sorunlara yol açan ve hastanın hayat kalitesini etkileyen, istemsiz idrar kaçırma olarak tanımlamıştır (4). Stress üriner inkontinans (SUi) efor, egzersiz veya karın içi basıncını artıran öksürme, gülme, hapşırma gibi aktiviteler esnasında istemsiz olarak idrar kaçırma; urge (sıkışma) tip inkontinans ise detrusor aşırı aktivitesinin sonucunda ortaya çıkan, tuvalete gitme ihtiyacı hissedildiği anda tuvalete ulaşamadan idrar kaçırma olarak tanımlanmaktadır. İleri yaş, multiparite, histerektomi öyküsü, menopoz ve ağır yük kaldırma ile ilişkili işlerde çalışmanın üriner inkontinans gelişimi için risk faktörleri olduğu saptanmış, ayrıca kronik olarak intra-abdominal ve intra-vezikal basınçta artışa neden olan obezitenin ise diğer risk faktörlerinden bağımsız olarak üriner inkontinansa neden olabileceği gösterilmiştir (5).

Erişkin kadın popülasyonunun \%30'unda üriner inkontinansa obezite eşlik etmekte, kilo verme ile üriner inkontinans sıklığ 1 ve şiddeti azalmaktadır (6). Obez kadınlarda sosyal, duygusal ve seksüel açılardan da hayat kalitesinin azaldığı birçok çalışma ile gösterilmiş fakat üriner inkontinans bulunan kadınlarda obezitenin seksüel fonksiyonlar ve hayat kalitesi üzerine etkisi hakkındaki araştırmalar kısıtlı kalmıştır $(7,8)$.

$\mathrm{Bu}$ çalışmada üriner inkontinans bulunan obez ve obez olmayan kadınların hayat kaliteleri ve seksüel fonksiyonları karşılaştırılmıştır.

\section{GEREÇ ve YÖNTEMLER}

$\mathrm{Bu}$ çalışmada Zonguldak Bülent Ecevit Üniversitesi Tıp Fakültesi Etik Kurulu'ndan onay alındıktan sonra (2020-1322/01) Ocak 2020-Nisan 2020 tarihleri arasında, Zonguldak Bülent Ecevit Üniversitesi Sağlık Uygulama ve Araştırma Merkezi Kadın Hastalıkları ve Doğum Anabilim Dalı, Kadın Hastalıkları Polikliniği’ne idrar kaçırma şikayeti ile başvuran kadınlar değerlendirilmiştir. Sorgu formlarını cevaplamayı kabul eden, 18 yaş ve üzerinde, seksüel olarak aktif olan hastalar çalışmaya dahil edilirken, sorgu formlarını eksik cevaplayan, nörolojik ve psikiyatrik hastalığı bulunan, evre 2 ve üzeri pelvik organ prolapsusu bulunan hastalar dışlanmıştır. Tüm katılımcılardan bilgilendirilmiş onam alınmıştır. Toplam 67 hastanın, Vücut Kütle indeksi (VKİ) $\geq 30 \mathrm{~kg} / \mathrm{m}^{2}$ olan 37 'si Obez grup, VKI $<30 \mathrm{~kg} / \mathrm{m}^{2}$ olan $31^{\prime} \mathrm{i}$ ise Obez olmayan grup olarak ayrılmıştır (9).

Hastaların demografik, obstetrik ve jinekolojik özellikleri kaydedilmiş, tüm hastalara dolu mesane ile litotomi pozisyonunda stress test, detaylı ürojinekolojik inceleme ve POP-Q muayenesi yapılmıştır. Digital palpasyon ile pelvik kas gücü değerlendirilmiş, sonuçlar 0-5 arasında puanlanmıştır.

Hayat kalitesi ve seksüel fonksiyonları değerlendirmek için İnkontinans Etki Anketi ('Incontinence Impact Questionnaire, IIQ-7), Ürogenital Distres Envanteri 
('Ürogenital Distress Inventory', UDI-6), Aşırı Aktif Mesane Anketi (Overactive Bladder Questionnaire, OAB-V8) ve Pelvik Organ Prolapsusu / Üriner İnkontinans Cinsel Anketi (Pelvic Organ Prolapse/Urinary Incontinence Sexual Questionnaire, PISQ-12) sorgu formları kullanılmıştır (1013). Çam ve ark. $(14,15)$ UDI-6, IIQ-7 ve PISQ-12 sorgularını Türk popülasyonu için doğrulamıştır. UDI-6, her maddesi 0-4 arası puanlanabilen, 6 sorudan oluşan, beşli Likert tipi bir ölçek; IIQ-7, her maddesi 0-3 arası puanlanabilen, 7 sorudan oluşan, dörtlü Likert tipi bir ölçektir. UDI-6 ve IIQ7 sorgularında elde edilen yüksek skorlar, hayat kalitesinin azalması ve üriner inkontinans şikayetlerinin ciddiyeti ile ilişkilidir. OAB-V8, urge inkontinans semptomlarını sorgulayan, her maddesi 0-5 arasi puanlanabilen, 8 sorudan oluşan, altılı Likert tipte bir ölçek olup toplam skor $\geq 8$ olması Aşırı Aktif Mesane tanısını desteklemektedir. PISQ-12 ise alt üriner sistem yakınmaları olan hastalarda seksüel fonksiyonları değerlendiren, her maddesi 0-4 arası puanlanan, 12 sorudan oluşan, beşli Likert tipi bir ölçektir. PISQ-12 skorunun yüksek olması seksüel fonksiyonlardaki iyilik ile ilişkilidir.

Çalışmanın istatistikleri SPSS 19.0 paket programında yapılmıştır. Nitel değişkenlere ait tanımlayıcı istatistikler frekans ve yüzde ile nicel değişkenler medyan, minimum ve maksimum değerleriyle verilmiştir. Normal dağılım göstermeyen nicel değişkenlerin iki grup arası karşılaştırmalarında Mann-Whitney U testi kullanılmıştır. Sürekli değişkenlerin normal dağılıma uygunluğu Shapiro-Wilk testi ile değerlendirilmiştir. Nitel değişkenlerin gruplar arası karşılaştırmalarında Yates Ki-Kare testi, parametreler arasındaki ilișkilerin incelenmesinde ise Pearson Korelasyon testi kullanılmıștır. Çalışmadaki tüm istatistiksel analizlerde $p$ değeri 0,05 'in altındaki sonuçlar istatistiksel olarak anlamlı kabul edilmiştir.

\section{BULGULAR}

Obez gruptaki 37 hasta ile obez olmayan gruptaki 31 hastanın demografik özellikleri karşılaştırılmış, sonuçlar Tablo 1'de gösterilmiştir. Yaş, gravida, parite, normal spontan doğum (NSD) sayısı, histerektomi öyküsü, menopozal durum, ek hastalık (hipertansiyon, diabetes mellitus, kronik obstruktif akciğer hastalığı) sıklığı açısından gruplar arasında fark gözlenmezken, sigara kullanımının obez olmayan grupta, obez gruba göre daha yüksek olduğu saptanmıştır (sırasıyla $\% 45,2$ ve $\% 2,7, \mathrm{p}<0,001)$.

Obez ve obez olmayan grupta en sik görülen üriner inkontinans tipi mikst inkontinanstı (sirasıyla \%54,1 ve \%38,7) (Tablo 2). SUİ, urge inkontinans ve mikst inkontinans görülme oranlarının her iki grupta da benzer olduğu görülmüştür (sırasıyla $\mathrm{p}=0,494 ; \mathrm{p}=0,308 ; \mathrm{p}=0,959$ ). Yapılan ürojinekolojik değerlendirmede, obez olan grubun $\% 62,2$ 'sinde ve obez olmayan grubun $\% 61,3$ 'ünde stress testi (+) olarak saptanmıştır $(\mathrm{p}=1,000)$. İşeme güçlüğü oranı, pelvik kas gücü, klitoral refleks ve anal refleks muayenelerinin her iki grupta da benzer olduğu görülmüştür.

Obez hastalarda, obez olmayan hastalara göre daha yüksek UDI-6 total skoru (sirasiyla 58,30 ve $29,16 \mathrm{p}=0,001$ ) ve daha yüksek OAB-V8 total skoru (sirasiyla 21,00 ve 12,00 $\mathrm{p}=0,002$ ) saptanmıştır. IIQ-7 total skorları açısından gruplar arasında fark gözlenmemiştir ( $\mathrm{p}=0,795)$. Öte yandan yüksek skorların seksüel fonksiyonlarındaki iyilik ile ilişkili olduğu PISQ-12 skorları ise obez olmayan grupta obez gruba göre anlamlı olarak daha yüksek olarak saptanmıştır (sırasıyla 28,00 ve $27,00 \mathrm{p}=0,026$ ) (Tablo 2).

VKİ ile üriner inkontinans şiddeti ve seksüel fonksiyonları yansitan sorgu formu skorları arasındaki korelasyon sonuçları Tablo 3'te gösterilmiştir. VKİ ile PISQ-12 skorları arasında zayıf negatif korelasyon $(\mathrm{r}=-0,296, \mathrm{p}=0,027)$, UDI-6

Tablo 1: Demografik ve klinik özellikler.

\begin{tabular}{|c|c|c|c|}
\hline & Obez $(n=37)$ & Obez olmayan $\quad(n=31)$ & $\mathbf{p}$ \\
\hline Yaş $^{x}$ & $51(33-72)$ & $49(37-64)$ & $0,167^{a}$ \\
\hline Gravida $^{x}$ & $4(2-10)$ & $4(1-7)$ & $0,324^{\mathrm{a}}$ \\
\hline Parite $^{x}$ & $3(1-8)$ & $3(1-5)$ & $0,705^{\mathrm{a}}$ \\
\hline NSD $^{x}$ & $3(0-8)$ & $2(1-5)$ & $0,749^{\mathrm{a}}$ \\
\hline Histerektomi öyküsü, n (\%) & $18(48,6)$ & $11(35,5)$ & $0,397^{\mathrm{b}}$ \\
\hline Menopoz, n (\%) & $24(64,9)$ & $15(48,4)$ & $0,262^{b}$ \\
\hline Hipertansiyon, $n(\%)$ & $18(48,6)$ & $14(45,2)$ & $0,966^{\mathrm{b}}$ \\
\hline Diabetes Mellitus, n (\%) & $2(5,4)$ & $2(6,5)$ & $1,000^{c}$ \\
\hline KOAH, n (\%) & $1(2,7)$ & $3(9,7)$ & $0,324^{\mathrm{c}}$ \\
\hline Sigara, n (\%) & $1(2,7)$ & $14(45,2)$ & $<0,001^{\mathrm{c}}$ \\
\hline
\end{tabular}

a: Mann-Whitney U testi; ${ }^{\mathbf{x}}$ medyan(minimum-maksimum), b: Yates ki kare testi; n(\%), c: Fisher kesin ki kare testi; n(\%) şeklinde. 
skorları ile orta derece pozitif korelasyon $(\mathrm{r}=0,431, \mathrm{p}<0,001)$ ve OAB-V8 skorları ile orta derece pozitif korelasyon $(\mathrm{r}=0,490, \mathrm{p}<0,001)$ saptanmıştır. Bununla beraber VKİ ile IIQ-7 skorları arasında ise korelasyon bulunamamıştır $(\mathrm{r}=0,049, \mathrm{p}=0,693)$.

\section{TARTIŞMA}

Seksüel fonksiyonlar genel hayat kalitesini etkileyen önemli faktörlerdendir (16). Özellikle de üriner inkontinanslı hastalarda seksüel fonksiyon bozuklukları asemptomatik kadınlara göre daha sık olarak görülmektedir (17). Üriner inkontinans şikayeti olan kadınlar cinsel ilişki sırasında idrar kaçırmaktan dolayı kendilerini suçlu hissetmekte ve bu nedenle partnerleriyle beraber olmaktan sakınmaktadırlar. Obezitenin de seksüalite ile ilişkili olduğu, obez kadınlarda seksüel disfonksiyonların daha sık görüldüğü bilinmektedir (18).

Çalışmada üriner inkontinans bulunan obez ve obez olmayan kadınların hayat kaliteleri ve seksüel fonksiyonları karşılaştırılmıştır. Obez kadınlarda üriner inkontinans semptomlarının daha fazla ve daha sık olduğu, fakat fiziksel aktivite, sosyal hayat ve duygu durumla ilişkili hayat kalitelerinin obez olmayan kadınlardan farksız olduğu saptanmıştır. Öte yandan üriner inkontinansı bulunan obez kadınların seksüel fonksiyonlarının, obez olmayan kadınlardan daha kötü olduğu görülmüştür.

Genel popülasyonda seksüel disfonksiyon prevalansının \%25-63 arasında olduğu bildirilmiştir (19). Üriner inkontinans bulunan kadınların inkontinans sıklığı ve miktarı, urge semptomlarının şiddeti ve noktüri bulunup bulunmaması hayat kalitesini ve seksüel fonksiyonları etkileyebilmektedir. 2017'de yayınlanan bir derlemede, mikst üriner inkontinansın, SUİ ya da urge inkontinanstan daha fazla kadın seksüel disfonksiyonu ile ilişkili olduğu gösterilmiştir. Öteyandan aşırı aktif mesane semptomlarının sıklığ ve şiddetinin de önemli olduğu, orgazm sırasında inkontinans görülmesinin detrusor aşırı aktivitesi ile ilgili olabileceği saptanmıştır (20). Benzer olarak bu çalışmada da istatistiksel olarak anlamlı olmasa da, PISQ-12 total skorları ile OAB-V8 total skorları arasinda negatif zayıf korelasyon bulunduğu saptanmıştır $(r=-0,225, p=0,065$, gösterilmemiş data).

Birçok çalışmada obez kadınların seksüel aktivitede doyumsuzluk yaşadıkları ya da seksüel aktiviteden kaçındıkları bildirilmiştir $(21,22)$. Obez kadınlarda negatif

Tablo 2: Ürojinekolojik muayene sonuçları, hayat kalitesi ve seksüel fonksiyon skorları.

\begin{tabular}{|c|c|c|c|}
\hline & Obez $(n=37)$ & Obez olmayan $(n=31)$ & $\mathbf{p}^{\mathbf{b}}$ \\
\hline Stress test (+) n (\%) & $23(62,2)$ & $19(61,3)$ & $1,000^{\mathrm{b}}$ \\
\hline İşeme güçlüğüu n (\%) & $11(30,6)$ & $7(22,6)$ & $0,647^{\mathrm{b}}$ \\
\hline Klitoral refleks (+) n (\%) & $36(97,3)$ & $31(100)$ & $1,000^{\mathrm{b}}$ \\
\hline Anal refleks (+) n (\%) & $36(97,3)$ & $30(96,8)$ & $1,000^{\mathrm{b}}$ \\
\hline Pelvik kas gücü̈ & $2(0-3)$ & $2(0-5)$ & $0,391^{\mathrm{a}}$ \\
\hline SUİ n (\%) & $4(10,8)$ & $6(19,4)$ & $0,494^{b}$ \\
\hline Mikst n (\%) & $20(54,1)$ & $12(38,7)$ & $0,308^{\mathrm{b}}$ \\
\hline Urge n (\%) & $13(35,1)$ & $12(38,7)$ & $0,959^{\mathrm{b}}$ \\
\hline UDI-6 $^{x}$ & $58,30(12,50-100)$ & $29,16(2,08-62,50)$ & $0,001^{\mathrm{a}}$ \\
\hline IIQ-7 ${ }^{x}$ & $47,57(0-104,65)$ & $42,81(0-85,62)$ & $0,795^{\mathrm{a}}$ \\
\hline OAB-V8 ${ }^{x}$ & $21,00(0-40,00)$ & $12,00(0-29,00)$ & $0,002^{\mathrm{a}}$ \\
\hline PISQ-12 ${ }^{\mathrm{x}}$ & $27(0-46,00)$ & $28,00(13,00-43,00)$ & $0,026^{a}$ \\
\hline
\end{tabular}

a: Mann-Whitney U testi; ${ }^{x}$ medyan(minimum-maksimum), b: ki kare testi; $\mathrm{n}(\%)$.

Tablo 3: VKİ’nin hayat kalitesi, üriner inkontinans şiddeti ve seksüel fonksiyonları yansıtan sorgu formu skorları ile korelasyonu.

\begin{tabular}{cccccc}
\hline & PISQ-12 & UDI-6 & OAB-V8 & IIQ-7 \\
\hline VKİ $^{a}$ & & & & & \\
& $\mathbf{r}^{\mathbf{b}}$ & $\mathbf{- 0 , 2 9 6}$ & $\mathbf{0 , 4 3 1}$ & $\mathbf{0 , 4 9 0}$ & 0,049 \\
& $\mathbf{p}$ & $\mathbf{0 , 0 2 7}$ & $<\mathbf{0 , 0 0 1}$ & $<\mathbf{0 , 0 0 1}$ & 0,693 \\
\hline
\end{tabular}

${ }^{\text {a } V u ̈ c u t ~ k u ̈ t l e ~ i n d e k s i, ~}{ }^{\text {b }}$ Pearson korelasyon katsayısı. 
genel vücut imajı algısı ve obezitenin pelvik taban üzerine olası negatif etkileri, seksüel disfonksiyon sebebi olabilir. Obezitenin üriner inkontinansın önemli bir risk faktörü olduğu bilinmesine karşın, obezitenin üriner inkontinansı bulunan hastaların seksüel fonksiyonları üzerine etkisi kısıtl düzeyde araştırılmıştır. Kadın Cinsel Fonksiyon İndeksi (Female Sexual Function Index) sorgusu kullanılarak yapılan iki çalışmada, üriner inkontinansı bulunan obez kadınların yarıdan fazlasında seksüel disfonksiyon bulunduğu gösterilmiştir $(23,24)$. Bilgiç ve ark. yaptıkları çalışmada üriner inkontinansı bulunan obez kadınların hayat kalitesi ve seksüel fonksiyonlarının obez olmayanlardan daha kötü olduğunu saptamışlardır (25). Diğer çalışmalardan farklı olarak, bu çalışmada üriner inkontinansın hastaların hayat kaliteleri üzerine etkilerini gösteren IIQ-7 total skoru, obez ve obez olmayan kadınlar arasında farklılık göstermemiştir. $\mathrm{Bu}$ sonuç, obez kadınların obez olmayan kadınlara göre daha az sosyal ve fiziksel aktiviteye katılmaya yatkın ve istekli olabileceğinden, bu durum IIQ-7 skorunun daha az olarak puanlanmış olması ile açıklanabilir. Öte yandan, diğer çalışmalara benzer olarak bu çalışmada da seksüel disfonksiyon, üriner inkontinansı bulunan obez hastalarda obez olmayan hastalardan daha yüksek olarak saptanmıştır.

Üriner inkontinans bulunan kadınlarda, inkontinansın sıklığı ve şiddetinden bağımsız olarak obezitenin negatif etkisi ile seksüel disfonksiyon görülebilmektedir. Bu durum önemli olmasına rağmen, birçok kadın seksüel problemlerini dile getirmekte güçlük çekmektedir. Bu grup hastalarda seksüel disfonksiyon varlığının araştırılması sorunların öngörülebilmesine olanak sağlayarak hastaların hayat kalitelerinin artırılmasına olanak sağlayacaktır.

\section{Etik Kurul Onayı}

Zonguldak Bülent Ecevit Üniversitesi Tıp Fakültesi Etik Kurulu (2020-13-22/01)

\section{Çıkar Çatışması}

Herhangi bir çıkar çatışması yoktur.

Finansal Destek

Herhangi bir finans desteği alınmamıştır.

Yazarların Makaleye Katkı Beyanı

Çalışma dizaynı: Yeşim Akdemir, Verilerin toplanması: Yeşim Akdemir, Konul Novruzova, İstatistik: Çağatay Büyükuysal, Yazım: Yeşim Akdemir, Revizyon: Yeşim Akdemir, Mehmet İbrahim Harma, Müge Harma, Ülkü Özmen.

\section{Hakem Değerlendirmesi}

Kör hakemlik süreci sonrası yayınlanmaya kabul edilmiştir.

\section{KAYNAKLAR}

1. Dratva J, Go' mez Real F, Schindler C, et al. Is age at menopause increasing across Europe? Results on age at menopause and determinants from two population-based studies. Menopause. 2009;16:385-394.

2. Tam, AA, Cakir B. Approach of obesity in primary health care. Ankara Medical Journal. 2012;12(1):37-41.

3. Flegal KM, Graubard BI, Williamson DF, Gail MH. Causespecific excess deaths associated with underweight, overweight, and obesity. JAMA. 2007;298:2028-2037.

4. Andersen JT, Blaivas JG, Cardozo L, et al. ICS 7th report on the standardisation of terminology of lower urinary tract function-Lower urinary tract rehabilitation techniques. Neurourol Urodyn. 1992;11:593-603.

5. Subak LL, Richter HE, Hunskaar S. Obesity and Urinary Incontinence: Epidemiology and Clinical Research Update. J. Urol. 2009;182:S2-S7.

6. Barber MD. Pelvic organ prolapse. British Medical Journal. 2016;354;3853:1-9.

7. Monz B, Chartier-Kastler E, Hampel C, Samsioe G, Hunskaar S, Espuna-Pons M, Chinn C. Patient characteristics associated with quality of life in European women seeking treatment for urinary incontinence: Results from PURE. Europen Urology. 2007;51(4):1073-1081.

8. Muennig P, Lubetkin E, Jia H, Franks P. Gender and the burden of disease attributable to obesity. American Journal of Public Health. 2006;96(9):1662-1668.

9. Pomian A, Lisik W, Kosieradzki M, Barcz E. Obesity and pelvic floor disorders: A review of the literature. Medical Science Monitor. 2016;3(22):1880-1886.

10. Shumaker SA, Wyman JF, Uebersax JS, McClish D, Fantl JA. Health- related QOL measures for women with urinary incontinence: The incontinence impact questionnaire and urogenital distress inventory. Quality of Life Research. 1994 3(5):291-306.

11. Uebersax JS, Wyman JF, Shumaker SA, McClish D, Fantl JA. Short forms to assess life quality and symptom distress for urinary incontinence in women: The incontinence impact questionnaire and urogenital distress inventory. Neurourology and Urodynamics. 1995;14(2):131-139.

12. Acquadro C, Kopp Z, Coyne KS, et al. Translating overactive bladder questionnaires in 14 languages. Urology. 2006;67: 536-540.

13. Rogers RG, Coates KW, Kammerer-Doak D, Khalsa S, Qualls C. A short form of the Pelvic Organ Prolapse/Urinary Incontinence Sexual Questionnaire (PISQ-12). International Urogynecology Journal of Pelvic Floor Dysfunction. 2003; 14(3):164-168.

14. Cam C, Sakalli M, Ay P, Cam M, Karateke A. Validation of the short forms of the incontinence impact questionnaire (IIQ7 ) and the urogenital distress inventory (UDI-6) in a Turkish population. Neurourol Urodyn. 2007;26(1):129-133. 
15. Cam C, Sancak P, Karahan N, Sancak A, Celik C, Karateke A. Validation of the short form of the Pelvic Organ Prolapse/ Urinary Incontinence Sexual Questionnaire (PISQ-12) in a Turkish population. Eur J Obstet Gynecol Reprod Biol. 2009;146(1):104-107.

16. Moller LA, Lose G. Sexual activity and lower urinary tract symptoms. Int Urogynecol J Pelvic Floor Dysfunct. 2005;17:1821.

17. Dalpiaz O, Kerschbaumer A, Mitterberger M, Pinggera GM, Colleselli D, Bartsch G, et al. Female sexual dysfunction: A new urogynecological research field. BJU Int. 2008;101:717721.

18. Esposito K, Giugliano F, Ciotola M, De Sio M, D’Armiento M, Giugliano D. Obesity and sexual dysfunction, male and female. Int J Impot Res. 2008;20:358-365.

19. Ambler DR, Bieber EJ, Diamond MP. Sexual function in elderly women: A review of current literature. Rev Obstet Gynecol. 2012;5:16-27.

20. Serati M, Salvatore S, Uccella S, Cromi A, Khullar V, Cardozo $\mathrm{L}$, et al. Urinary incontinence at orgasm: Relation to detrusor activity and treatment efficacy. Eur Urol. 2008;54:911-917.
21. Kinzl JF, Trefalt E, Fiala M, Hotter A, Biebl W, Aigner F. Partnership, sexuality, and sexual disorders in morbidly obese women: Consequences of weight loss after gastric banding. Obes Surg. 2001;11:455-458.

22. Adolfsson B, Elofsson S, Rossner S, Unden AL. Are sexual dissatisfaction and sexual abuse associated with obesity? A population-based study. Obes Res. 2004;12:1702-1709.

23. Pace G, Silvestri V, Guala L, Vicentini C. Body mass index, urinary incontinence, and female sexual dysfunction: How they affect female postmenopausal health. Menopause. 2009; 16(6):1188-1192.

24. Huang AJ, Stewart AL, Hernandez AL, Shen H, Subak LL. Sexual function among overweight and obese women with urinary incontinence in a randomized controlled trial of an intensive behavioral weight loss intervention. Journal of Urology. 2009;181(5):2235-2242.

25. Bilgic D, Gokyildiz S, Kizilkaya Beji N, Yalcin O, Gungor Ugurlucan F. Quality of life and sexual function in obese women with pelvic floor dysfunction. Women Health. 2019;59(1):101-113. 